"SOCIALIZATION \& HUMAN DEVELOPMENT" INTERNATIONAL JOURNAL

\title{
EMPATHIC INTERACTION OF ADOLESCENTS: PSYCHOLOGICAL PECULIARITIES AND CORRELATES
}

https://doi.org/10.37096/SHDISJ-20-1.1-0009

\author{
Shistko L.O. \\ ORCID: 0000-0003-1972-5514 \\ Riabchych I.Y. \\ ORCID: 0000-0002-3216-5059 \\ Prokopovych Y.M. \\ ORCID: 0000-0002-8601-5419
}

\begin{abstract}
The goal of this article is to present the psychological peculiarities and correlates of the empathic interaction of adolescents. Methodology meet the following steps:the first was the diagnosis of empathy of the subjects and the frequency of manifestations of each type of empathy interpersonal interaction was determined; on the second were diagnosed cognitive, emotional, motivational and value-meaning individual-psychological qualities and features of young people, which are important for the situation of interpersonal interaction; in the third stage, the relationships between each type of empathic interpersonal interaction and the personal indicators of the subjects were determined. For this purpose, the Pearson linear correlation method was used. Seven species of the latter are described. An empathogenic situation is required to activate the empathy process. The latter refers to the intense production of emotions, emotions, moods, thoughts, states of personality that resonate with the corresponding mental processes and states of other people. The received signals about the inner state на another person is only information perceived by the individ. The effective response to this information will depend on the needs that dominate in the personality structure. Discussion shows that from the outlined point of view, we believe that depending on different circumstances (the level of empathy as an integrative indicator, as well as actual (situational) needs and states of personality), information about the internal state of another may be perceived by actualizing a certain type of empathic response, or not perceived. The dissonant interaction is characterized by a confronting psychological position, nonconformist cognitive orientation, low level of emotional maturity, manifested in low control of emotions and indistinct manifestation, pessimistic emotional modality, eccentric modality. All these characteristics were accompanied by the lack of need to interact and the depreciation of the Other.
\end{abstract}

Keywords: empathy, empathic, empathogenetic situation, empathic interpersonal interaction, young age.

\section{Introduction}

Interpersonal interaction is an integral part of a person's life. Its effectiveness often depends on the measure of subjective well-being and psychological comfort of the individual, the success of comprehensive self-realization and so on (Prokopovych, 2017; Riabchych, 2018). In this context, finding ways to improve the effectiveness of interpersonal relationships 
is of particular importance. Under such conditions, research into empathic interpersonal interaction may be a promising area of scientific search.

A review of scientific sources showed that the vast majority of scientists (I. Bech, N. Bulatevich, I. Danyliuk, L. Zhuravleva, O. Zaporozhets, N. Kalina, I. Kozytska, A. Mambetova, Y. Prokopovych, I. Riabchych, S. Shykovets, O. Vlasova, etc.) consider empathy in the context of interpersonal interaction, but no comprehensive experimental study of their relationship has been conducted.

The article purpose is to present to present the psychological peculiarities and correlates of the empathic interaction of adolescents.

\section{Theoretical background}

Research has shown that empathy permeates every element of interpersonal interaction. Its updating at one stage or another directly affects the nature of its course. The peculiarities of this influence are determined by the level of empathy development of the subjects of interpersonal interaction. Thus, depending on whether empathy during interpersonal contact was actualized or not, any interpersonal interaction can be divided into empathic or non-empathic.

Empathic interaction means the accidental or intentional, private or public, long-term or short-term, verbal or nonverbal, direct or indirect personal contact of two or more people during which the empathy of at least one of the subjects of the interaction is actualized (Danyliuk, Kozytska \& Shykovets, 2018; Shykovets, Mambetova, 2018).

According to L. Zhuravleva (Zhuravl'ova, 2007: 40), an empathogenic situation is required to activate the empathy process. The latter refers to the intense production of emotions, emotions, moods, thoughts, states of personality that resonate with the corresponding mental processes and states of other people. According to the basic principles of the information theory of emotions, the received signals about the inner state of another is only information perceived by the individual. The effective response to this information will depend on the needs that dominate the personality structure (Simonov, 1981). From the outlined point of view, we believe that depending on different circumstances (the level of empathy as an integrative indicator, as well as actual (situational) needs and states of personality), information about the internal state of another may be perceived by actualizing a certain type of empathic response, or not perceived (Vlasova, 2019; Bulatevich, Mambetova, 2018). If it is not perceived by the individual, then the empathic process is not actualized and in this particular situation or interpersonal interaction does not occur at all, or non-empathetic interpersonal interaction is implemented. If, however, a person has perceived and realized this information about another, then interpersonal interaction will be implemented in accordance with actualized forms of empathy (Zhuravl'ova, 2007). Consider possible options for its development:

1. The personality was aware of the inner state of the other, but her attention was shifted by a more significant stimulus. At first glance, empathic engagement never happened. At the same time, we see that the empathic process was started, but was interrupted initially. In this case, empathy was realized in the form of indifference. Therefore, we can talk about interrupted (indifferent) empathic interaction.

2. The person realized the inner state 
"SOCIALIZATION \& HUMAN DEVELOPMENT" INTERNATIONAL JOURNAL

of the other, there was an emotional switch from his experiences to his own, the mechanism of identification worked, there was empathy. However, the immersion in one's own experiences has gone so deep that the experiences of another have lost their relevance. In this way, self-centered empathic interpersonal interaction was realized.

3. The personality was aware of the inner state of the other, there was an emotional switch from his experiences to his own, the mechanism of identification worked, there was an empathy that was amenable to reflection. Reflected information facilitated the assessment of the situation, the decentration and the emergence of emotions regarding the inner state of the empath (personality, which intensively produces emotions, emotions, moods, thoughts, states). An empathic person (a person who perceives information about emotions, emotions, moods, thoughts, states of empathy and responds to them in some way) felt sympathy, compassion and more. If the affective sphere is dominant in the personality structure, then the empathic process at this stage may be interrupted. This kind of empathetic interpersonal interaction is subject-centric.

4. Feeling sympathetic or empathetic to one's personality there is a need for assistance. It models different options for assistance, selects resources, develops an internal action plan, and more. An empathic person has an intention that is not always embodied in real action. The kind of empathic interpersonal interaction in which real assistance does not take place is called intentional.

5. If the intention is embodied in the process of interaction, taking into account their own interests (not to harm them), then a conducive empathic interaction is realized.

6. When a person helps another, leveling their desires, needs, interests, we can talk about the realization of altruistic empathic interpersonal interaction.

7. It is often the case that when one perceives information about another's inner state, one's emotions and aspirations arise in the personality, which are opposite to the empath's experiences and needs. In this case, anti-empathy was actualized, which can be realized on several levels: from anger or gloating and to real counteraction, or even sadistic pleasure from the feeling of suffering of the Other (Zhuravl'ova, 2007: 49-67). Anti-empathy, as well as empathy, has its functions, mechanisms, determinants, forms of manifestation, etc. that have yet to be established. Since we have not encountered such research, we consider it possible to combine all forms of anti-empathy into one type of empathic interpersonal interaction - dissonant. Note that with the advent of the classification of forms of dissonant empathy, it will be quite natural to further differentiate dissonant empathic interaction.

A person's propensity to engage in one or another type of empathic interpersonal interaction can be determined by various factors. We can distinguish at least three of them:

1. Objective, which include the complexity of the empathogenic situation, the conditions in which it occurs, the presence of other people, age, gender of the empath, family ties with him, etc.

2. Situational to which we refer the mood of the empathic, the extent of his concern and the nature of activity at the moment of the empathogenic situation, the reactions of others to it, etc.

3. Subjective relating to the individual 
"SOCIALIZATION \& HUMAN DEVELOPMENT" INTERNATIONAL JOURNAL

characteristics and qualities of the empathic personality.

If the first and the second species are difficult to predict and investigate (due to innumerable variations), the latter factor is easily empirically studied.

\section{Methodology}

Methodology

(Sample, Instruments/Methods, Procedure) meet the following steps:

- the first was the diagnosis of empathy of the subjects and the frequency of manifestations of each type of empathy interpersonal interaction was determined;

- on the second were diagnosed cognitive, emotional, motivational and value-meaning individual-psychological qualities and features of young people, which are important for the situation of interpersonal interaction;

- in the third stage, the relationships between each type of empathic interpersonal interaction and the personal indicators of the subjects were determined. For this purpose, the Pearson linear correlation method was used.

The study used the following techniques: "Empathy test for adolescents and adolescents" by L. Zhuravleva (Zhuravleva, 2010), "Subjective evaluation of interpersonal relationships" S. Dukhnovsky (Dukhnovsky, 2009), "Dialogue of Interpersonal Relations" by S. Dukhnovsky (Dukhnovsky, 2009), "Diagnosis of Motivational Orientations in Interpersonal Communication" by I. Ladanov and V. Urazaeva (Fetiskin, Kozlov \& Manujlov, 2002: 68), "Diagnosis of emotional barriers in interpersonal communication" V. Boyko (Fetiskin, Kozlov \& Manujlov, 2002: 118), "Diagnosis of interactive personality orientation" by N. Shchurkov in modification by N. Fetiskin (Fetiskin,
Kozlov \& Manujlov, 2002: 59), "The Need for Communication" by O. Eliseev (Eliseev, 2001), "The Communication Direction Questionnaire (UFO)" S. Bratchenko (Bratchenko, 1997).

The study involved 120 adolescents. Statistical processing of data was carried out using the SPSS software package.

\section{Results}

As a result of the analysis of the empirical material obtained, a system of reliable correlates of the above types of empathic interpersonal interaction identified above (see Table 1) was revealed. Thus, statistically significant correlates of interrupted empathic interpersonal interaction are such indicators of the cognitive component of interpersonal interaction as cognitive styles of psychological orientation $(\mathrm{r}=-0.218 ; \mathrm{p}$ $\leq 0.001)$ and reflexive assessment of one's own "I" as a social percept $(\mathrm{r}=-0.154$; $\mathrm{p}$ $\leq 0.05$ ). Among the indicators of the emotional component revealed a reliable relationship only with the emotional modality of interaction $(\mathrm{r}=-0,263 ; \mathrm{p} \leq$ $0,001)$, and the motivational - with the affective $(\mathrm{r}=-0,122 ; \mathrm{p} \leq 0,1)$ and selfish $(r=0,122 ; p \leq 0,1)$ motivational orientation, as well as the need for interaction $(\mathrm{r}=-$ $0,105 ; \mathrm{p} \leq 0,1)$. The value-meaning component revealed statistically significant interconnections of interrupted empathic interaction with the alterocentric $(\mathrm{r}=-$ $0.284 ; p \leq 0.001)$, dialogic $(r=-0.239 ; p$ $\leq 0.001)$, authoritarian $(\mathrm{r}=0.116, \mathrm{p} \leq 0.1)$, manipulative $(\mathrm{r}=0,187 ; \mathrm{p} \leq 0,01)$ and indifferent $(r=0,104 ; p \leq 0,1)$ value-sense orientation.

Qualitative analysis of the results showed that for persons who implement interrupted empathic interaction inherent in the autonomy of judgment, indifference to the opinion of others, rigidity, suspicion, 
"SOCIALIZATION \& HUMAN DEVELOPMENT" INTERNATIONAL JOURNAL

sense of helplessness and hopelessness, low level of need for interaction, vivid expression, vivid expression, business cooperation, selfish motivational orientation. We believe that all these characteristics can be both individual personality traits (those that manifest themselves in the vast majority of personal interactions), and situational (occur in a specific situation with a specific Other). We assume that the presence of at least one of these indicators increases the likelihood of indifferent behavior in an empathic situation.
In addition, we can observe that the largest number of correlates of indifferent empathy interaction is concentrated in the value-semantic component of interpersonal interaction. Obviously, the most valuable relationship to the Other is the key to this type of interaction. Therefore, indifferent interaction is possible only when the Other is not of value to the empathic, and therefore his thoughts, experiences, feelings, etc. lose their significance. Conversely, if empathy is a significant personality, then more developed types of empathic interpersonal interaction are likely to be realized.

Table 1. Matrix of significant linear correlation coefficients between empathy interaction components and interpersonal interaction components in adolescence

\begin{tabular}{|c|c|c|c|c|c|c|c|c|}
\hline Components & $\begin{array}{c}\text { Indicat } \\
\text { or }\end{array}$ & $\mathbf{P}$ & $\mathbf{E}$ & $\mathbf{C}$ & $\mathbf{H}$ & Cn & $\mathbf{A}$ & D \\
\hline \multirow[t]{4}{*}{ Cognitive } & CSD & & & 181 & & & -143 & \\
\hline & CSP & & -111 & & & & & 153 \\
\hline & CBS & $-218 *$ & & -120 & & $24^{*}$ & 131 & -116 \\
\hline & ROI & 154 & & & & & & 132 \\
\hline \multirow[t]{9}{*}{ Emotional } & KEM & & & $\underline{177}$ & & -134 & -164 & \\
\hline & NP & & & & & & & \\
\hline & NNEM & & 182 & & & -184 & -142 & 132 \\
\hline & DAY & & & & & -145 & & \\
\hline & NZL & & & & & & -194 & \\
\hline & EMB & & 124 & 137 & & -174 & -164 & 106 \\
\hline & EMV & & & 143 & & & -109 & \\
\hline & EMM & $-263 *$ & -152 & -15 & & $293 *$ & $184^{*}$ & $-226^{*}$ \\
\hline & EMC & & & & & & & 107 \\
\hline \multirow[t]{6}{*}{ Motivational } & EgMO & 122 & & & & -149 & & $223 *$ \\
\hline & AFMO & -122 & -196 & & & 176 & & $-287 *$ \\
\hline & QMS & & & 116 & & & & 159 \\
\hline & $\mathrm{PV}$ & -105 & -169 & & & & $207 *$ & $-225^{*}$ \\
\hline & SS & & -166 & & & 134 & 106 & \\
\hline & $\mathrm{BV}$ & & -108 & & & 133 & & \\
\hline \multirow{7}{*}{$\begin{array}{l}\text { Values and } \\
\text { semantics }\end{array}$} & $\mathrm{Av}$ & 116 & & 139 & & & $-0,233^{*}$ & \\
\hline & $\mathrm{M}$ & $\underline{187}$ & & & & -153 & & 138 \\
\hline & $\mathrm{Al}$ & $-284 *$ & & & & & -143 & $-238 *$ \\
\hline & $\mathrm{K}$ & & & -12 & & 122 & & 174 \\
\hline & Ind & 104 & & & & & 131 & $22 *$ \\
\hline & $\mathrm{E}$ & & & & & & & -117 \\
\hline & $\mathrm{D}$ & $-239 *$ & -108 & -17 & & $296^{*}$ & -164 & -161 \\
\hline
\end{tabular}

Notes: 1) zeros and commas are omitted; 2 ) italicized level of significance $p \leq 0,1$; bold $-\mathrm{p} \leq 0.05$; 
underlined - $\left.\mathrm{p} \leq 0.01{ }^{*}-\mathrm{p} \leq 0.001 ; 3\right)$ CSD - cognitive styles of psychological distance; CSP - cognitive styles of psychological position; CBS - cognitive styles of psychological orientation; ROI is a reflective assessment of one's self as a social percept; KEM - inability to manage emotions, dispense them; NP is an inadequate expression of emotions; NNEM - inflexibility, underdevelopment, lack of expression of emotions; DAY - dominance of negative emotions; NZL - reluctance to approach people emotionally; EMB - emotional barriers; EMV - emotional involvement; EMM - emotional modality; EMC emotional orientation; EgMO - selfish motivational orientation; AFMO - Affirmative Motivational Orientation; QMS - situational motivational orientation; PV need for interaction; SS - targeting for social approval; BV - a focus on conflict-free interaction; Av - authoritarian value-meaning orientation; M - manipulative value-meaning orientation; Al - alterocentric value-semantic orientation; Kconformal value-meaning orientation; Ind - indifferent value-semantic orientation; E - equal valuesemantic orientation; D - dialogical value-semantic orientation; 4) P - interrupted empathic interaction; $\mathrm{E}$ is an egocentric empathic interaction; $\mathrm{C}$ - subjectocentric empathic interaction; $\mathrm{H}$ - intentional empathic interaction; $\mathrm{Cn}$ - promoting empathic interaction; $\mathrm{A}$ - altruistic empathic interaction; $\mathrm{D}$ is a dissonant empathic interaction.

The study of correlates of selfcentered empathic interaction revealed the presence of relationships with indicators of cognitive styles of psychological position $(\mathrm{r}=-0,111 ; \mathrm{p} \leq$ $0,1)$, reflective assessment of one's self as a social percept $(\mathrm{r}=-0,159 ; \mathrm{p} \leq 0,05)$, emotional modality $(\mathrm{r}=0,152 ; \mathrm{p} \leq 0,05)$, emotional immaturity $(\mathrm{r}=0,124 ; \mathrm{p} \leq$ $0,05)$, manifested in inflexibility, underdevelopment, fuzzy emotions $(\mathrm{r}=$ $0,182 ; \mathrm{p} \leq 0,01)$, affiliate $(\mathrm{r}=-0.196 ; \mathrm{p}$ $\leq 0.001)$ motivational orientation, engagement needs $(r=-0.169 ; \mathrm{p} \leq 0.01)$, social approval target $(\mathrm{r}=-0.166$; $\mathrm{p} \leq 0.01)$, mot non-conflict interaction $(\mathrm{r}=$ $-0.108 ; \mathrm{p} \leq 0.1)$ and dialogical valuemeaning orientation $(\mathrm{r}=-0.108 ; \mathrm{p} \leq 0.1)$.

Thus, self-centered empathic interpersonal interaction in adolescence is characterized by a compassionate psychological position, a pessimistic emotional modality, and indifference to others. Realizing this type of interaction, the person does not feel an urgent need to communicate with another, is not guided by the thoughts and needs of the latter, and accordingly, is not concerned with the development of relationships with him. Obviously, having a natural capacity for empathy, when an empathic situation occurs, the empathic process in such people is triggered. However, due to emotional immaturity, which in this case manifests itself in inflexibility, underdevelopment, lack of expression of emotions, it is impossible to activate the mechanism of emotional decentration, without which the transition to more developed types of empathic interpersonal interaction is impossible. At the same time, it should be noted that the vast majority of correlates of egocentric empathic interaction are concentrated in the motivational component. Assume that this type of interaction is more driven by a system of motives that are in the plane "for themselves" or "for others." In the first embodiment, self-centered interaction will be implemented, and in the second, more complex forms of empathic interaction.

When analyzing the correlates of subject-centric empathic interaction, it was found that the latter is in direct statistically significant relation to the cognitive style of psychological distance $(r$ $=0,181 ; \mathrm{p} \leq 0,01)$, emotional immaturity $(\mathrm{r}$ $=0,137 ; \mathrm{p} \leq 0,05$ ), which is caused by the inability to manage emotions, dispense them $(r=0,177 ; p \leq 0,01)$, emotional 
involvement in interaction $(\mathrm{r}=0,143$; $\mathrm{p} \leq 0,05), \quad$ situational motivational orientation $(\mathrm{r}=0,116 ; \mathrm{p} \leq 0,1)$ and dominance setting $(\mathrm{r}=0.139 ; \mathrm{p} \leq 0.05)$. The inversely statistically significant relationship was found with cognitive styles of psychological orientation $(\mathrm{r}=-$ $0.12 ; \mathrm{p} \leq 0.1)$, emotional modality of interaction $(\mathrm{r}=-0.15 ; \mathrm{p} \leq 0.05)$, attitudes toward subjugation of authority $(r=0.12$; $\mathrm{p} \leq 0.1)$ and dialogical value-meaning orientation $(\mathrm{r}=-0.172 ; \mathrm{p} \leq 0.01)$.

\section{Discussion}

Thus, we see that the subject-centric empathic interaction is characterized by the concentration of its correlates in the emotional component. This is quite natural, because this type of interaction is mainly realized on an emotional level. This is facilitated by a pessimistic emotional modality ("in this situation you will not help anything, you just have to sympathize ...") (Zhuravl'ova, 2007: 42), a high level of emotional involvement in interaction, which can sometimes grow into emotional jam. The latter may be due to the inability of the empathic to manage emotions, dispense them.

In addition, for this type of empathy interaction is characterized by the activation of cognitive processes that provide such mechanisms of empathy as personal and moral reflection, assessment of the situation. Since the process of reflection involves a certain juxtaposition of the society in order to compare its own behavior with its norms, it is quite natural here to have a non-conformist cognitive orientation and cognitive distance from others. The process of assessing the situation also requires some removal.

The functioning of the mechanism for updating the settings at this stage of the empathic process explains the existence of reliable interconnections with the valuesemantic component of interpersonal interaction: in particular, the setting for dominance, the lack of setting for the subjugation of authority and the lack of dialogue. Explaining the positive relationship of subject-centric interaction with a dominance setting is quite difficult. We assume that this setting reflects the willingness of the empathic to be an active participant in this interaction. Without this installation, he would remain a mere spectator who may be worried about the empath, but does not interact with it.

The negative correlation with the attitudes of authority and dialogue is quite clear. Thus, in the first case, the greater the willingness to submit to a reputable Other, the lower will be the concentration on the position of the empath. Dialogical interaction implies the perception of the Other as an equal subject, the creator of one's life. This perception of the Other would require the expectation of some, probably, joint action to resolve the situation, not just sympathy.

Quite unexpected were the results of the search for correlates of intentional empathic interpersonal interaction, as we could not find any.

We assume that the transition from intent to concrete action is governed not so much by the personal characteristics of the empathic, but by situational or objective factors.

In terms of facilitating empathic interpersonal interaction, its correlates are indicators of all components of interpersonal interaction. Yes, this type of empathic interaction correlates positively with cognitive styles of psychological orientation. In particular, facilitative interaction is characterized by a constructive psychological orientation $(\mathrm{r}=$ 
$0.24 ; \mathrm{p} \leq 0.001$ ), which provides cognitive attitudes to the mutual satisfaction of the subjects of the interaction according to the situation. That is why the empathic responds to the empathogenic situation in such a way as to help the other and not harm their own interests.

This kind of interaction is impossible with the emotional immaturity of the empathic $(\mathrm{r}=-0.174 ; \mathrm{p} \leq 0.01)$, in particular in such manifestations of the latter as inability to control emotions, dispense them $(\mathrm{r}=-0.134 ; \mathrm{p} \leq 0.05)$, dominance of negative emotions $(r=-$ 0.145; $\quad \mathrm{p} \leq 0.05), \quad$ inflexibility, underdevelopment, fuzzy emotions, $(\mathrm{r}=-$ $0.184 ; \mathrm{p} \leq 0.01$ ), as evidenced by the negative correlation of the contributing empathic interaction with these indicators of the emotional component. Instead, we found a significant correlation with emotional modality $(r=0.293 ; p \leq 0.001)$, which indicates the tendency of people who implement a facilitating interaction to be optimistic about their life (empathogenic) situation, their willingness to overcome obstacles.

In the motivational component, a positive correlation was found with affiliative motivational orientation $(\mathrm{r}=$ $0.176 ; \mathrm{p} \leq 0.01$ ), social approval target ( $\mathrm{r}$ $=0.134 ; \mathrm{p} \leq 0.05)$, and compromise interaction $(\mathrm{r}=0.133 ; \mathrm{p} \leq 0,05)$. A negative correlation was also found with selfish motivational orientation $(\mathrm{r}=-$ $0.149 ; \mathrm{p} \leq 0.05)$. Therefore, the motives for facilitating interaction can be directed at developing interaction with empaths, on positive evaluation of one's own behavior by other participants in the empathogenic situation (including empaths), on reaching a compromise between the needs of empaths and one's own interests. The selfish motivational orientation hinders the realization of this type of empathic interaction.

In the value-semantic sphere of the person realizing the empathetic interaction, a valuable attitude towards the other is revealed. This is evidenced by the presence of a positive correlation with the dialogical $(\mathrm{r}=0.296 ; \mathrm{p} \leq 0.001)$ and conformal $(\mathrm{r}=$ $0.122 ; p \leq 0.1)$ value-meaning orientation and the inverse - with the manipulative $(r=$ $-0.153 ; p \leq 0.05$ ).

The next stage was devoted to the study of altruistic interpersonal interaction. Because it is the most advanced type of empathic response, and to provide it, the most complex mechanisms of empathy that have a cognitive, emotional, motivational nature are activated, its correlates are indicators of all components of interpersonal interaction. In particular, a significant correlation was found with such indicators of the cognitive component as cognitive styles of psychological distance $(\mathrm{r}=-$ $0.143 ; \mathrm{p} \leq 0.05)$ and directionality $(\mathrm{r}=$ $0.131 ; \mathrm{p} \leq 0.05)$. Therefore, altruistic interaction will be characterized by a cognitive orientation to psychological closeness and a constructive style of interaction development.

The emotional component revealed a significant relationship with optimistic emotional modality $(r=0,184 ; p \leq 0,001)$, emotional involvement $(\mathrm{r}=-0,109$; $\mathrm{p} \leq 0,1)$ and emotional immaturity $(\mathrm{r}=-$ $0,164 ; p \leq 0,01)$. Indeed, to help the Other by risking one's own interests (and sometimes one's own health or even one's life) requires a high level of emotional involvement, for which the fear of the Other, the pity for one, etc., dominates the experience for one's own well-being. At the same time, going for self-sacrifice, according to the law of self-preservation, 
the empathic person simply has to believe in achieving the desired result. Conversely, an individual will not be able to actually contribute to self-harm if he / she is unable to manage his / her emotions, dispense them, does not want to emotionally attach to others, and is not emotionally labile. That is, the emotional immaturity that manifests itself in all sorts of emotional barriers hinders the feeling of the Other and the subsequent emotional attachment.

Regarding the value-semantic component, centering on the Other $(\mathrm{r}=$ $0.24 ; \mathrm{p} \leq 0.001)$ and setting on dialogic interaction are characteristic for the realization of altruistic interpersonal interaction. Instead, authoritarian $(\mathrm{r}=-$ $0.233 ; \mathrm{p} \leq 0.001)$ and indifferent $(\mathrm{r}=-$ $0.142 ; \mathrm{p} \leq 0.05$ ) values and values impede the realization of this type of empathic interaction. Such a result is quite natural, since self-sacrifice by its very nature presupposes a leveling of one's own interests for the sake of the welfare of the Other. Such an empathic response is only possible if one values and interacts with the Other. Thus, we conclude that altruistic interaction is more likely when the interaction between empath and empath is realized at the relationship level.

As proof of the above thesis is the correlates of the motivational component of interpersonal interaction. These include the need for engagement $(r=0.207$; $\mathrm{p} \leq 0.01$ ), and the goal of social approval $(r=0.106 ; p \leq 0.1)$. There is no doubt that if we value a person, he is important to us, then we need to be close to that person. In order to satisfy this need, it is necessary that this person also reciprocates. Hence the desire to please the Other, to look good in his eyes.

The highest number of correlates among the diagnosed indicators of interpersonal interaction was found in the study of dissonant interpersonal interaction. This is due to the fact that this type of interaction included all possible forms of anti-empathy, which can be realized at the level of personal-sense and transcendental empathy. Thus, the mechanisms that ensure the functioning of these forms were combined, which prevented the ability to isolate the dominant component of interpersonal interaction. Thus, in the empirical study it was found that the dissonant interaction is characterized by a confronting psychological position, non-conformist cognitive orientation, low level of emotional maturity, manifested in low control of emotions and expression of their emotions, pessimistic emotions, orientation, selfish or marginal motivational orientation. All this is accompanied by the lack of need for interaction and the depreciation of another person.

\section{Conclusion}

The study met the following steps: the first was the diagnosis of empathy of the subjects and the frequency of manifestations of each type of empathy interpersonal interaction was determined; on the second were diagnosed cognitive, emotional, motivational and valuemeaning individual-psychological qualities and features of young people, which are important for the situation of interpersonal interaction; in the third stage, the relationships between each type of empathic interpersonal interaction and the personal indicators of the subjects were determined. For this purpose, the Pearson linear correlation method was used. Analyzing the peculiarities of the interconnections of all kinds of empathic 
"SOCIALIZATION \& HUMAN DEVELOPMENT" INTERNATIONAL JOURNAL

interaction with some of the individualpsychological characteristics of adolescence, we can state:

1. Indifferent empathy interaction is most related to indicators of the valuesemantic component of interpersonal interaction, self-centered - motivational, subject-centered - emotional.

2. Encouraging, altruistic, and dissonant empathic interactions should correlate across all components of interpersonal interaction.

3. Intentional empathic engagement with any of the studied metrics is unrelated.

The raised topic needs further research.

Conflict of interests. There is no real conflict of interests at the time of writing this article or potential conflicts of interest for authors with responsible persons or any other person third parties on the subject matter of the article and related areas of legal research.

Acknowledgments. The study did not receive a grant from any financial agency in state, commercials or the nonprofit sector.

\section{References}

Bratchenko S. L. (1997). Diagnostika lichnostno-razvivajushhegosja

potenciala. Metodicheskoe posobie dlja shkol'nyh psihologov [Diagnostics of personalitydeveloping potential. Methodical manual for school psychologists.]. Pskov. S. 34 -56. [in Russian].

Bulatevich N., Mambetova A. (2018). Psychological peculiarities of parenthood apprehensions of Ukrainians and Crimean Tartars. International Journal of Education \& Development, 1, 13 - 24.

Danyliuk I. V., Kozytska I. V. \& Shykovets S. O. (2018). The cultural syndrome "Individualism

collectivism"and its psychological peculiarities including well-being of regional communities representatives in Ukraine. Scientific journal "Fundamental and applied research in practice of leading scientific schools", 30, 6, 55 -61 .

Duhnovskij S. V. (2009). Diagnostika mezhlichnostnyh Psihologicheskij

[Diagnostics otnoshenij. praktikum relationships. interpersonal Practical Training ] / Duhnovskij S.V. - SPb.: Rech'. 141. [in Russian].

Eliseev O. P. (2001). Praktikum po psihologii lichnosti [Practical work on personality psychology ]. SPb.: Piter. 560. [in Russian].

Zhuravl'ova L. P., Kolomiec' T.V. (2013). Empatijna determinacija kognitivnih stiliv mizhosobistisnoji vzaemodiji u junac'komu vici [The empathic determination of cognitive stiles of inter-personal interaction at the juvenile age ] // Problemi zagal'noji ta pedagogichnoji psihologiii: $\mathrm{Zb}$. nauk. prac' Institutu psihologiji im. G.S. Kostjuka APN Ukrajini, [za red. S. D. Maksimenka]. - K. T. XV, ch. 1. - S. 104 - 112. [in Russian].

Zhuravl'ova L. P. (2007). Psihologija empatiji: Monografija [The psychology of empathy]/Zhuravl'ova L.P. - Zhitomir: Vid-vo ZhDU im. I. Franka. 328. [in Ukrainian].

Fetiskin N. P. Kozlov, V. V. \& Manujlov G. M. (2002). Social'nopsihologicheskaja diagnostika razvitija lichnosti $i$ malyh grupp [The social-psychological diagnostics of development of 
personality and small groups ] / Sost. N.P. Fetiskin, V V. Kozlov, G.M. Manujlov. M.: Izd-vo instituta psihoterapii. 490. [in Russian].

McLaughlin K. A., King K. (2015). Developmental trajectories of anxiety and depression in early adolescence. J. Abnorm. Child Psychol. $\quad 43$ 311-323. 10.1007/s10802-014-9898-1

Moilanen K. L., Rasmussen K. E., PadillaWalker L. M. (2015). Bidirectional associations between self-regulation and parenting styles in early adolescence. J. Res. Adolesc. 25 246-262. 10.1111/jora.12125

Prokopovych Y. (2017). Psykholohichna kharakterystyka mikrosotsialnykh chynnykiv internet-zalezhnoi povedinky pidlitkiv [Psychological characteristics of microsocial factors of adolescent Internetdependent behavior]. Visnyk Kyivskoho natsionalnoho universytetu imeni Tarasa Shevchenka. Psykholohiia - Bulletin of Taras Shevchenko National University of Kyiv. Psychology, 2, 116 - 120 [in Ukrainian].

Riabchych I. (2018). Psykholohiia obdarovanosti [Psychology of giftedness]. Kyiv: «TsP «KOMPRYNT» [in Ukrainian].

Shykovets S.O., Mambetova A.A. (2018). Psychological features of the representatives' identity in the regional communitiesof Ukraine and Poland. Naukovyi Visnyk Khersonskoho Derzhavnoho Universytetu. Psykholohiia Scientific Bulletin of Kherson State University. Psychology, 3, 1, 142 148.

Tully E. C., Ames A. M., Garcia S. E., Donohue M. R. (2016). Quadratic associations between empathy and depression as moderated by emotion dysregulation. J. Psychol. 15015 35. 10.1080/00223980.2014.992382

Van der Graaff J., Carlo G., Crocetti E., Koot H. M., Branje S. (2018). Prosocial behavior in adolescence: gender differences in development and links with empathy. J. Young people Adolesc. 47 1086-1099. 10.1007/s10964-017-0786-1

Van Lissa C. J., Hawk S. T., Koot H. M., Branje S., Meeus W. H. J. (2017). The cost of empathy: parentadolescent conflict predicts emotion dysregulation for highly empathic young people. Dev. Psychol.53 1722-1737. 10.1037/dev0000361

Vlasova O. I. (2019). Influence of internet dependency on young people selfactualization. Socialization \& Human Development: International Scientific Journal,1, 1, 5-12. 